\title{
Matlab simulations for power factor correction of switching power
}

\author{
Ren Kaichun, He Chunhan, Su Dan, Wang Yongli, Zhang Xingqi \\ Liu Xiaojun, Gong Lihong, Zhao Ying and Liu Peng \\ Chongqing Communication College
}

China

\section{Definition of Power Factor}

Definition of power factor is:

$$
P F=\frac{P}{\mathrm{~S}}=\frac{U_{1} I_{1} \cos \phi_{1}}{U_{1} I_{R}}=\frac{I_{1} \cos \phi_{1}}{I_{R}}=\gamma \cos \phi_{1}
$$

In formula (1), $P F$ is power factor, $P$ is active power, $S$ is apparent power, $I_{1}$ is effective value of fundamental component of input current, $I_{R}$ is effective value of AC power source current, $I_{R}=\sqrt{I_{1}^{2}+I_{2}^{2}+\cdots+I_{n}^{2}}, I_{1}, I_{2}, \ldots, I_{n}$ are effective value of harmonic components of input current, $U_{1}$ is effective value of fundamental component of input AC voltage, $\gamma$ is deformation factor of input current, $\phi_{1}$ is the angel between the input AC voltage and fundamental component of the input current.

It is clear that the power factor PF is determined by $\gamma$ and $\phi_{1}$. The bigger the $\phi_{1}$, the bigger the reactive power is, the bigger the wastage of conductive line wire and transformer is. The smaller the $\gamma$, the bigger the input current harmonics of is, which will cause current distortion, produce pollution to electric grid, and even damage the electric equipments if condition is serious.

\section{Input Circuit and Its Power Factor of Single-Phase AC/DC Switching Power Supply}

Single-phase AC/DC switching power replaces the low frequency transformer of traditional power source with high frequency transformer, so it has such advantages as light weight, small size, and high power density etc. At the same time, the switching power has higher 
efficiency than the linearly-regulated DC power because its main power elements work as high frequency switches, so its application range is wider and wider.

The input circuit of traditional single-phased AC/DC switching power is demonstrated as Figure 1, after the mains supply(commercial power) is bridge rectified by D1 D4, it takes advantage of big electric capacity $\mathrm{C}$ to carry on smooth filtering to get DC voltage, and then transformed by DC/DC to realize insulation and voltage changing to supply the load. In simulation, use equivalent resistance $\mathrm{R}$ to replace the latter DC/DC and load as shown in the Figure 2.

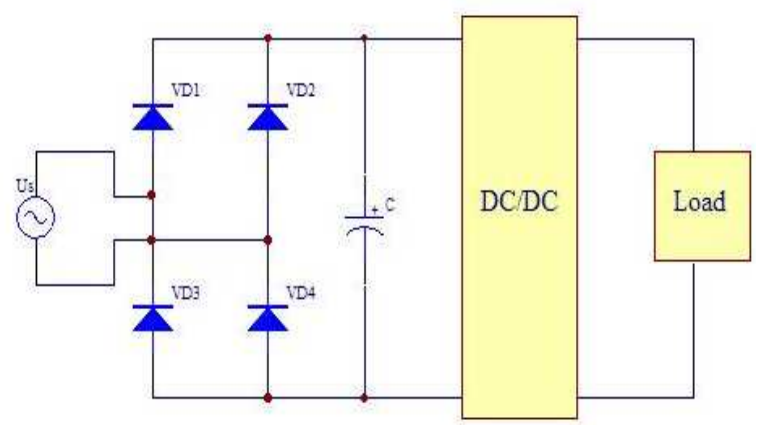

Fig. 1. Input circuit of AC/DC switch power supply

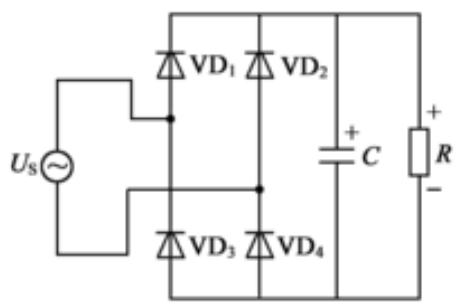

Fig. 2. Input equivalent electric circuit of AC/DC switching power supply

The emulated electric circuit that uses MATLAB structure is shown as Figure 3. The SCOPE module is used to observe the input voltage and current wave form; the current measuring module is used to check input current and then calculate the current effective value $I_{R}$, fundamental wave's effective value $I_{1}$ and included angel between input voltage and current fundamental component $\varphi_{1}$, and at last use formula (1) to calculate the power factor. 


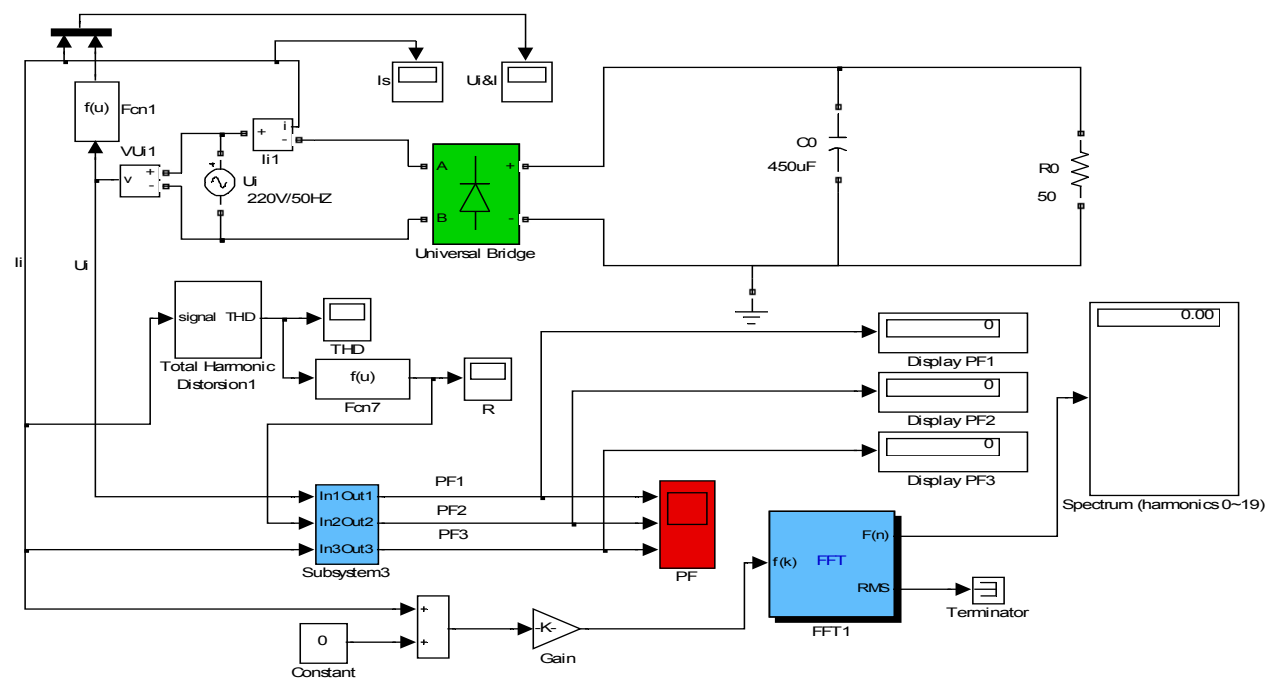

Fig. 3. Emulated circuit figure for input circuit of AC/DC switching power

The wave forms of input voltage and current are shown as Figure 4 . There are current pass through the rectifier diode D1 D4 only when input alternating voltage bigger than the voltage between the two ends of filter capacitor, so the input current presents in sharp impulse form, the distortion factor of wave form $\gamma$ is small, power factor PF is small, usually 0.6 0.7, and then the electric grid and other electric equipments are polluted and disturbed. In 1982, the IEC laid down a regulation IEC55-2 to limit higher harmonic (the later modified one is IEC1000-3-2), and made many power electronics technicians start to study harmonic filtering and PFC. The English full name for PFC is "Power Factor Correction".

There are two kinds of PFC, one is passive PFC, and the other is active PFC. Passive PFC(PPFC) only use capacitance, diode, inductance and other passive elements. The circuit is simple, and the cost is low, but the power factor of passive PFC is not very high that can only reach 0.7 0.8; APFC need to use transistor and controlling IC, the cost of which is much higher than that of PPFC. But the AC input current wave totally conform with such standard limits provision as IEC1000-3-2 etc. And can fundamentally realize unit power factor (when power factor is 1, it is called unit power factor). As a result, active BOOST correcting circuit is used much widely.

This following will introduce several kinds of passive PFC and active PFC. 


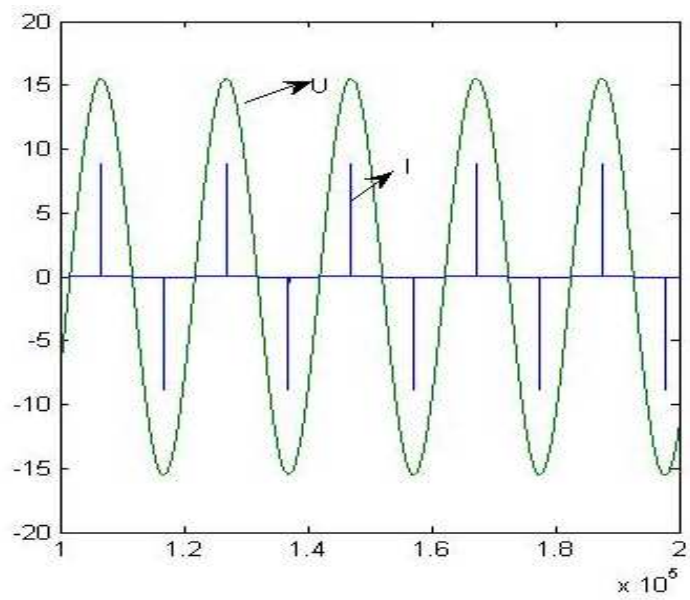

Fig. 4. Wave forms of input voltage and current

\section{Correcting circuit of passive power factor with large inductance}

Correcting circuit of passive power factor with large inductance is as Figure 5. The current and voltage wave form are shown as Figure 6, and its power factor is 0.898 . If adopting infinite inductance, then the current wave form will be as Figure 7, and the power factor reaches to 0.901 .

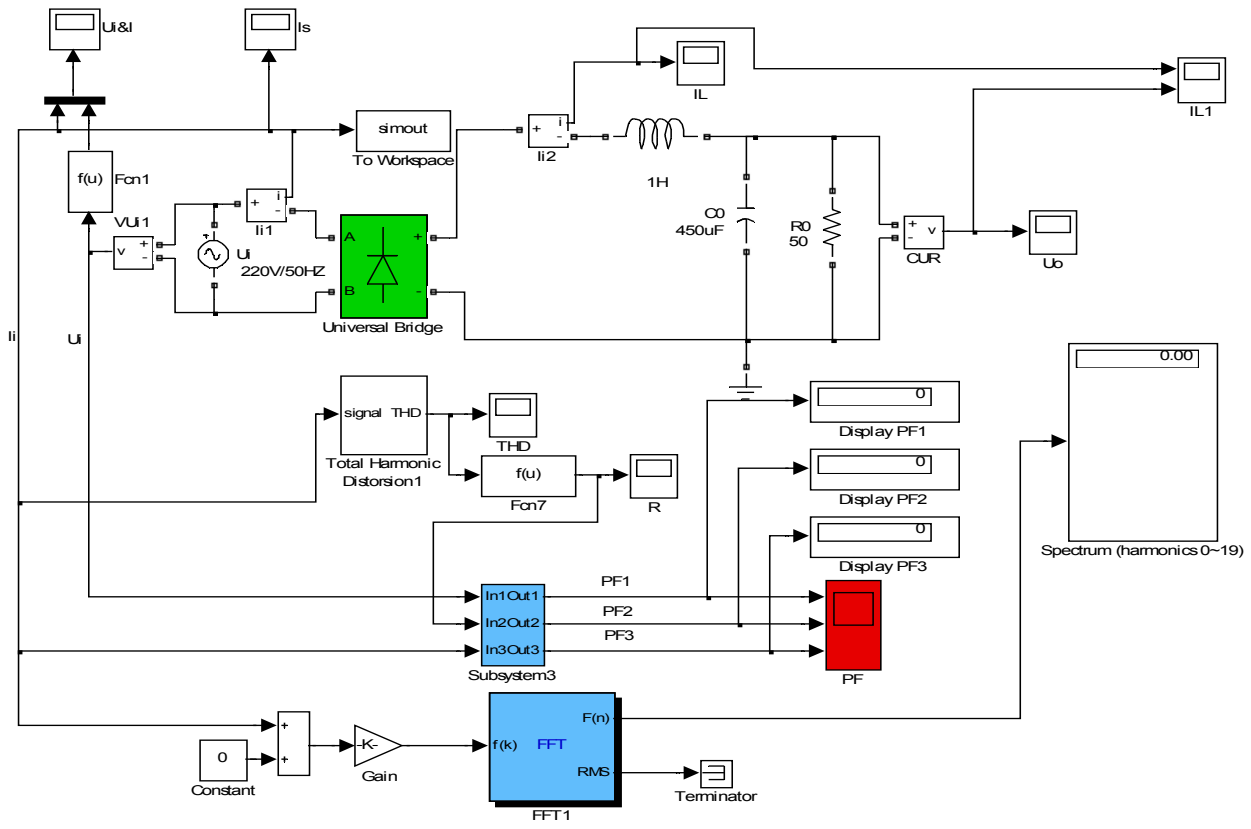

Fig. 5. Correcting circuit of passive power factor with large inductance 


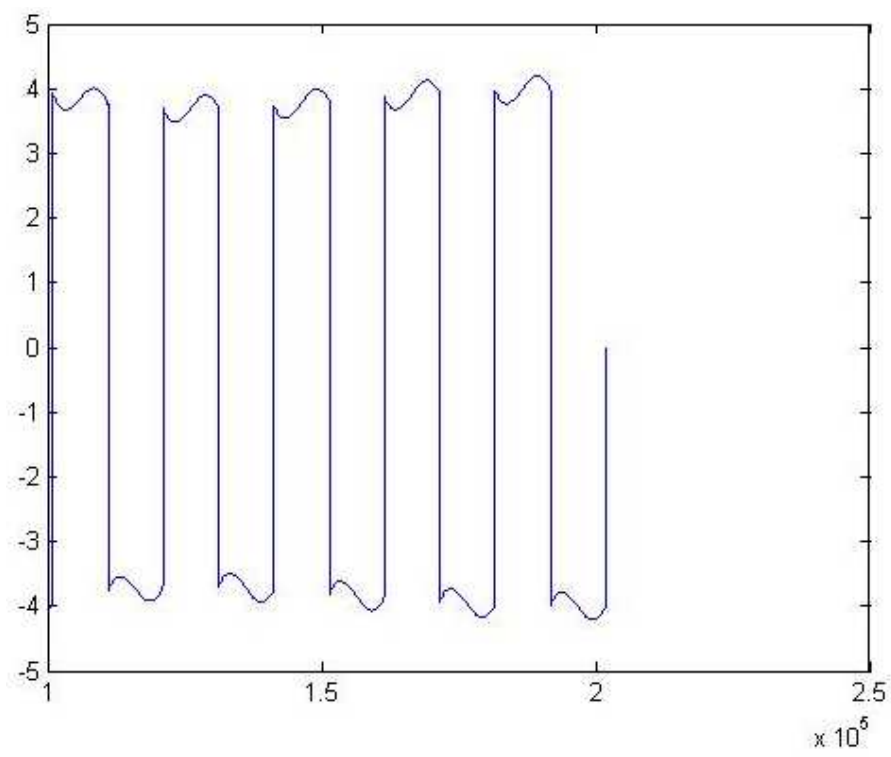

Fig. 6. Current wave form of large inductance

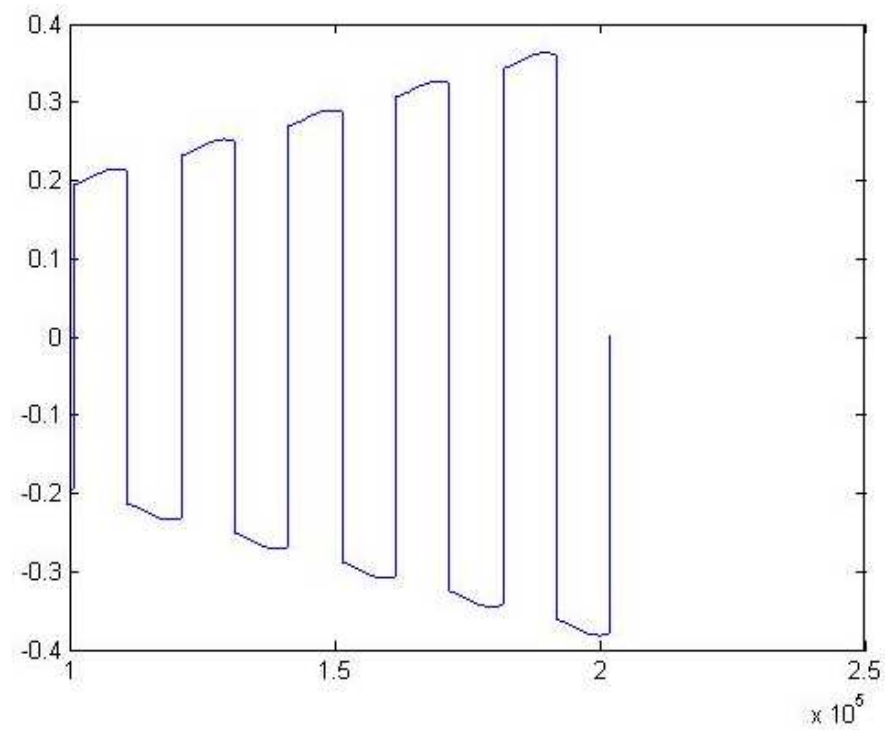

Fig. 7. Current wave form of infinite inductance

Using large inductance to correct power factor has such advantages as simple circuit, high reliability, and no extra frequency disturbing; But its drawback is it is cumbersome, the effect of power factor correcting is not very satisfied, and the correcting effect is inferior when the load range is relatively wide. 


\section{Correcting Circuit of Valley-filled Passive Power Factor}

The basic structure of valley-filled PFC is demonstrated as Figure 8 . When the input voltage is higher than the voltage between the two ends of the capacity, then the two capacities are charged in series; when the input voltage is lower than the voltage in the two ends of the capacity, the two capacities are discharging in parallel, which magnifies the conduction angle of diode, and then improves the current wave form and the power factor. The voltage and current waves by using MATLAB simulation are demonstrated as Figure 3 . And the different power factors under different loads are shown as table 1.

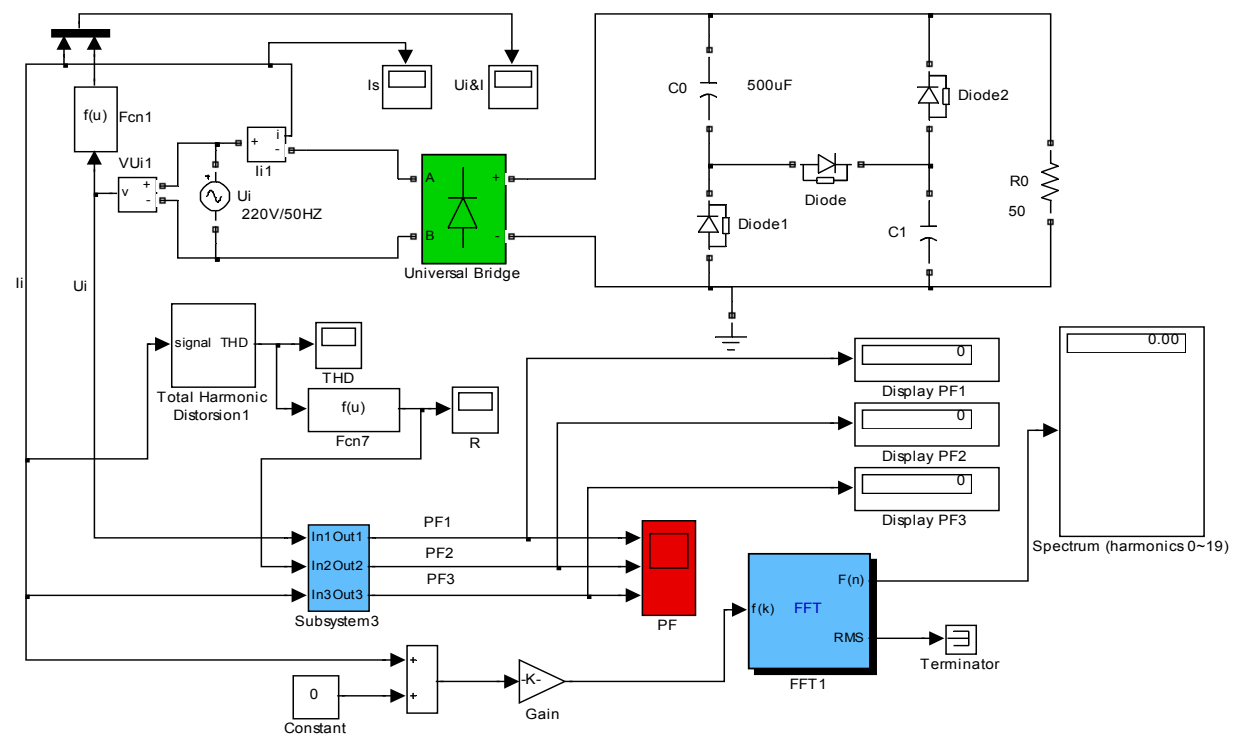

Fig. 8. Basic structure of valley-filled PFC rectification circuit

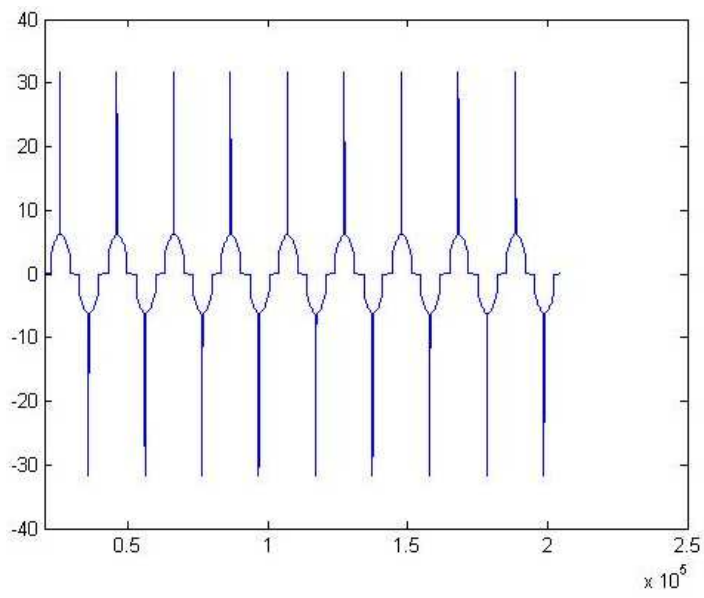

Fig. 9. Current wave form of valley-filled PFC 


\begin{tabular}{|l|l|l|l|l|l|l|l|l|}
\hline $\begin{array}{l}\text { Load Resistance } \\
\text { /Ohm }\end{array}$ & 40 & 60 & 80 & 100 & 120 & 140 & 160 & 180 \\
\hline Power Factor & 0.9112 & 0.8946 & 0.8836 & 0.8749 & 0.8644 & 0.8446 & 0.8442 & 0.8174 \\
\hline
\end{tabular}

Table 1. Power factors of valley-filled PFC under different loads

From Figure 9, we can see that valley-filled PFC current wave form is still not very satisfied, so, literature 5 put forward a kind of improved circuit as Figure 10. Its current wave form demonstrates as Figure 11. Compared with Figure 9, the current wave form is improved evidently, and the power factor is also been improved, and its power factors under different loads are shown as in table 2.

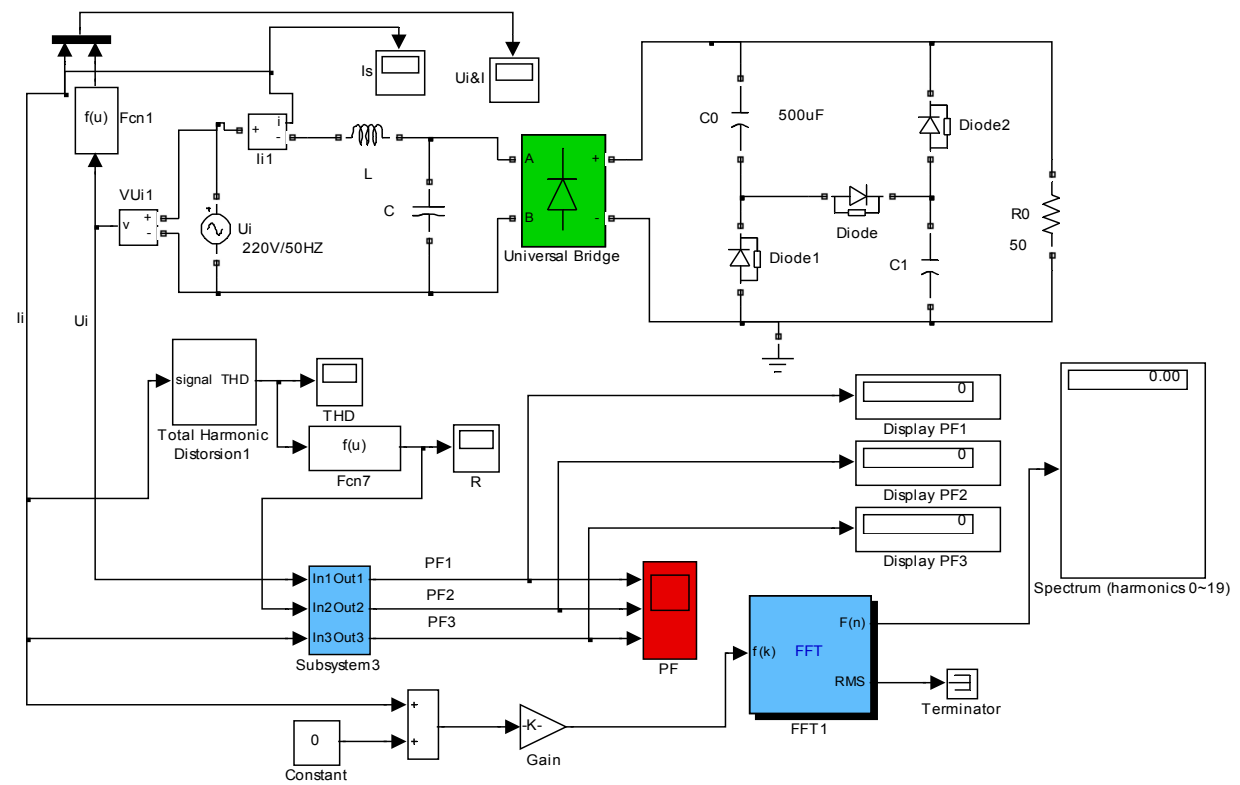

Fig. 10. An improved valley-filled PFC circuit 


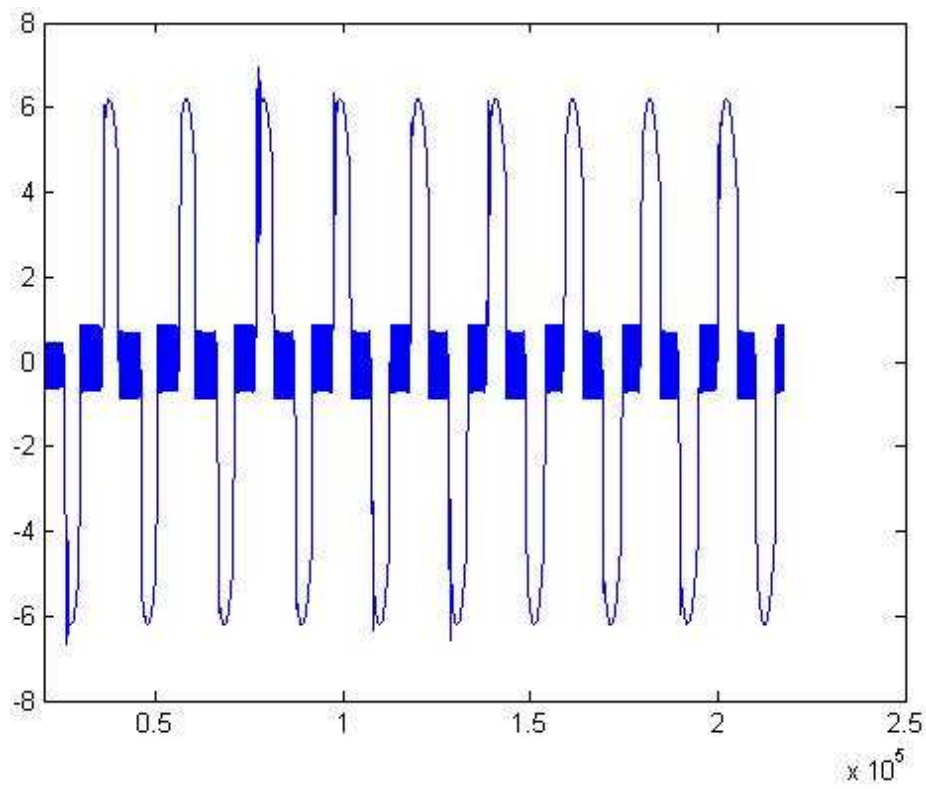

Fig. 11. an improved current wave form of valley-filled PFC circuit

\begin{tabular}{|l|l|l|l|l|l|l|l|l|}
\hline $\begin{array}{l}\text { Load Resistance } \\
\text { /Ohm }\end{array}$ & 40 & 60 & 80 & 100 & 120 & 140 & 160 & 180 \\
\hline Power Factor & 0.9554 & 0.9502 & 0.9421 & 0.9396 & 0.9345 & 0.9304 & 0.9285 & 0.9202 \\
\hline
\end{tabular}

Table 2. Power Factors of the improved valley-filled PFC under different loads

We can see that this kind of improved valley-filled PFC can evidently improve the power factors by comparing table 1 and table 2. Valley-filled PFC has been used in electronic ballast and other small electronic equipment, which can meet the requirements for power factor of low power electronic equipments of IEC1000-3-2 and other standards.

\section{Correcting Circuit and its Limit Power Factor of Active Power based on BOOST Circuit[1]}

BOOST active correcting circuit is demonstrated as Figure 12, $U_{A}$ is sampled current, $U_{B}$ is sampled full wave voltage and alternating voltage effective value, $U_{C}$ is MOSFET driving impulse, and $U_{D}$ is sampled output voltage. When the circuit operates in steady state, voltage $U_{B}$ is similar to full wave voltage, current of inductance $\mathrm{L}$ is similar to full wave current, the current is similar to sine current, and is similar to mains supply voltage, of same frequency and phase, and then make switching power factor approached to unit one. 


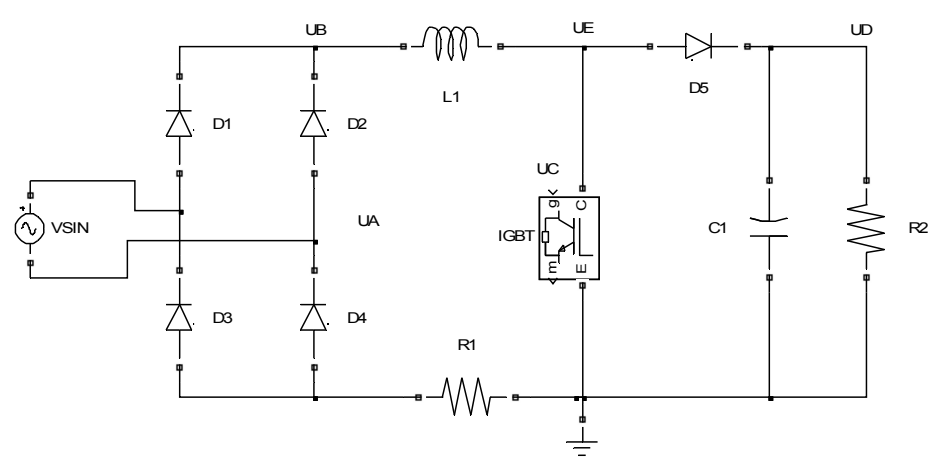

Fig. 12. BOOST active correcting circuit

BOOST active correcting circuit's power factor is smaller than 1. This conclusion is proved by counter evidence. i.e., assuming the circuit in Figure 12 has corrected the power factor to unit one, and then $U_{B}$ should be full wave voltage, current of inductance $L_{1}$ should be full wave current, and same as $U_{B}$ in wave form. Then the circuit can be emulated as Figure 13. This circuit uses current source (peak value is $12 \mathrm{~A}$ ) to replace, $I G T B, D_{5}$, $C_{1}, R_{2}$ in Figure 12, and this current source has same wave forms with inductive current. The R1 in Figure 13 is the resistance added in order to avoid iteration divergence, but it is evidently that the effect to emulation results can be ignored. The emulation results are shown as Figure 14. From Figure 14, we can see that $V_{\text {out }}$ appears minus voltage that is obviously impossible. Because the peak value of $U_{E}$ in Figure 12 is similar and almost equivalent to $U_{D}$, and its valley value is 0 , the low frequency component of $U_{E}$ e could not be minus. And thus it is proved that the BOOST active correcting circuit power factor of the BOOST active correcting circuit is always smaller than 1 .

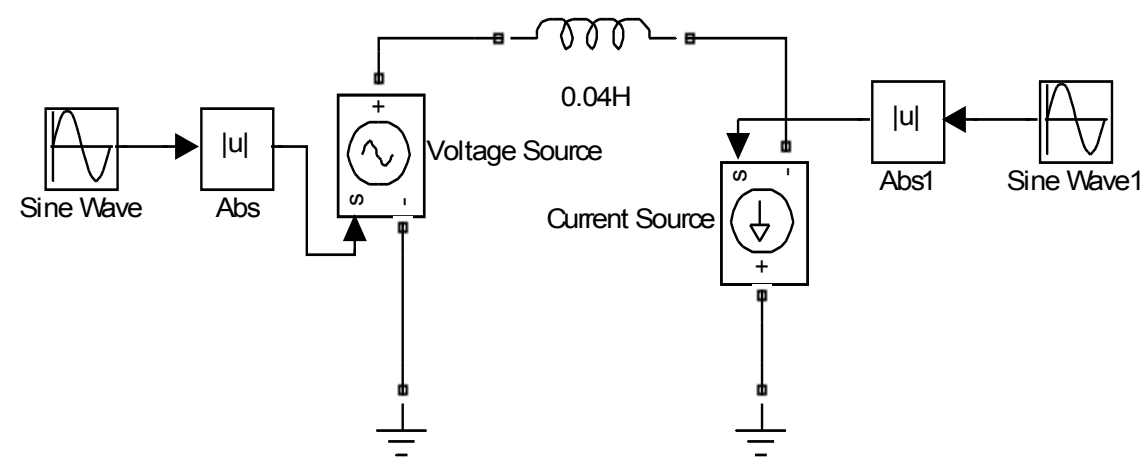

Fig. 13. Emulated circuit to prove the limit power factor of BOOST which is smaller than unit one 
Now, we are going to calculate power factor's limit of BOOST active correcting circuit. The emulated circuit is demonstrated as in Figure 14, the diode D5 is added in order to delete the minus part of VOUT in Figure 13, and this conforms to actual application. Its voltage and current wave forms are demonstrated as the Figure 15. And we can see from the Figure that except the current wave near the zero point is "a little" deflected from the sine wave, all the other places are very close to it.

L1

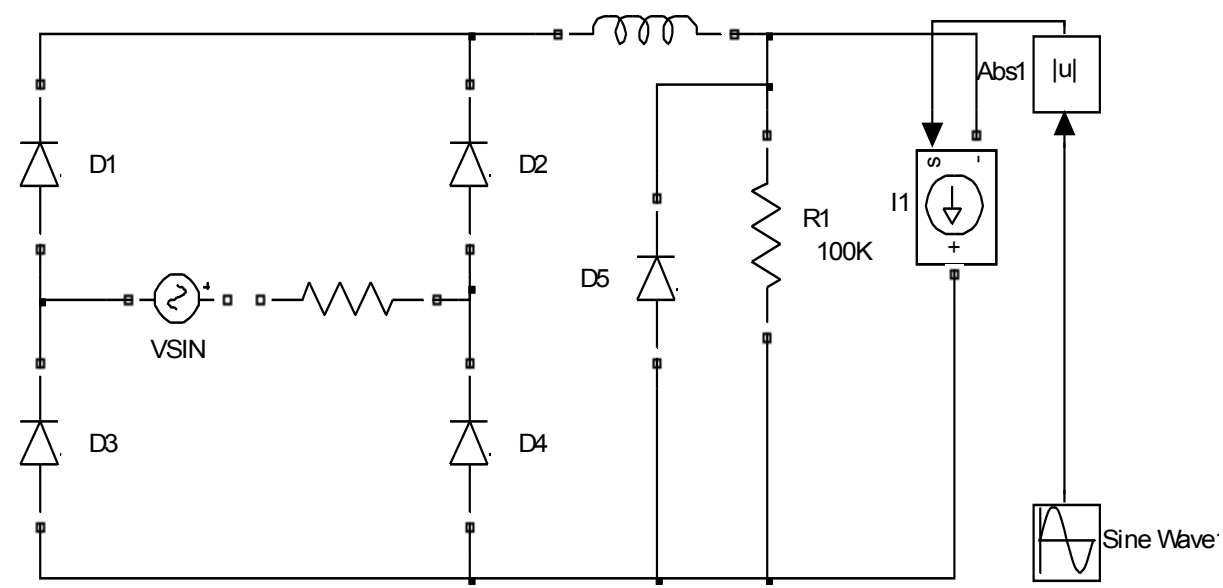

Fig. 14. Emulated circuit that calculating the power factor's limit of BOOST active correcting circuit

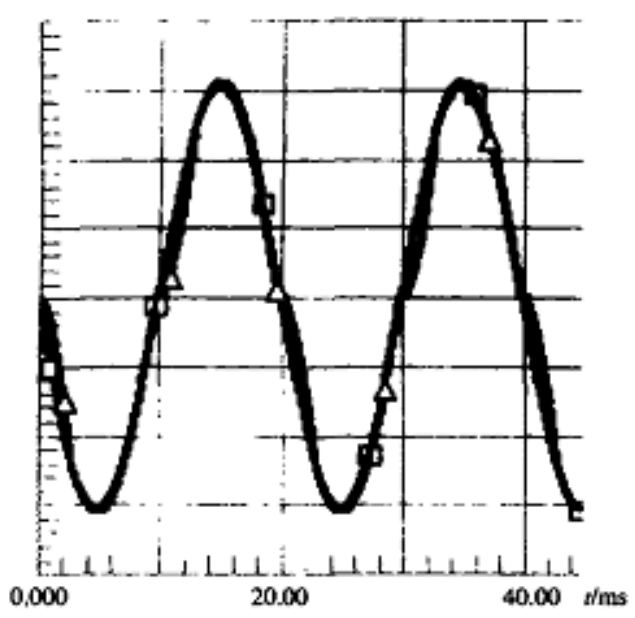

Fig. 15. Voltage and current wave form 


\section{Correcting Circuit of Active PFC based on BOOST Circuit}

BOOST active correcting circuit is demonstrated as Figure 12, and its emulated circuit is demonstrated as Figure 16. The module li1 is used to detect current, the module ls is to display current, The module Vuil is used to calculate voltage, the module Ui\&I is to display voltage and current, the module Subsystem 3 is used to calculate power factor according to formula (1), the module $\mathrm{fft} 1$ is used to calculate elements of harmonic wave, RS is current sampling resistor, the module Ii 2 is to detect current of inductance, the module Subsystem is controlling module that adopts average current control mode. The module Subsystem 3 is demonstrated as Figure 17.

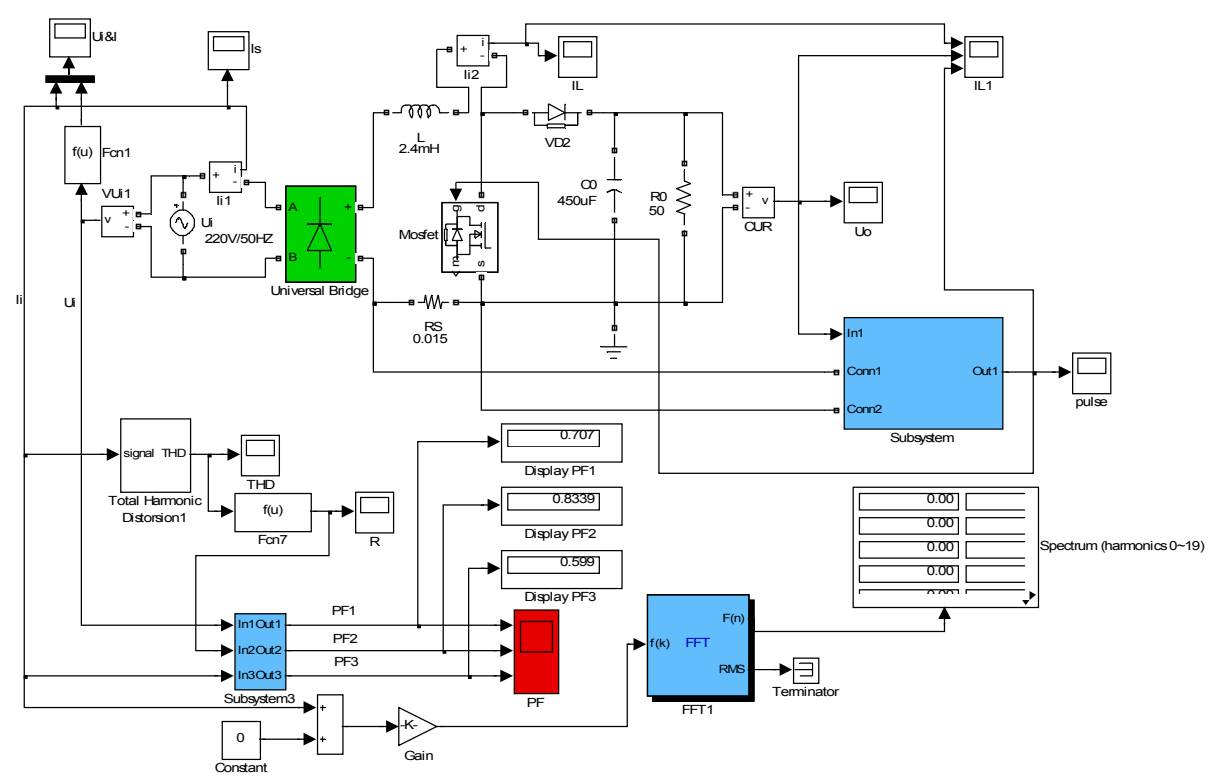

Fig. 16. BOOST active correcting circuit

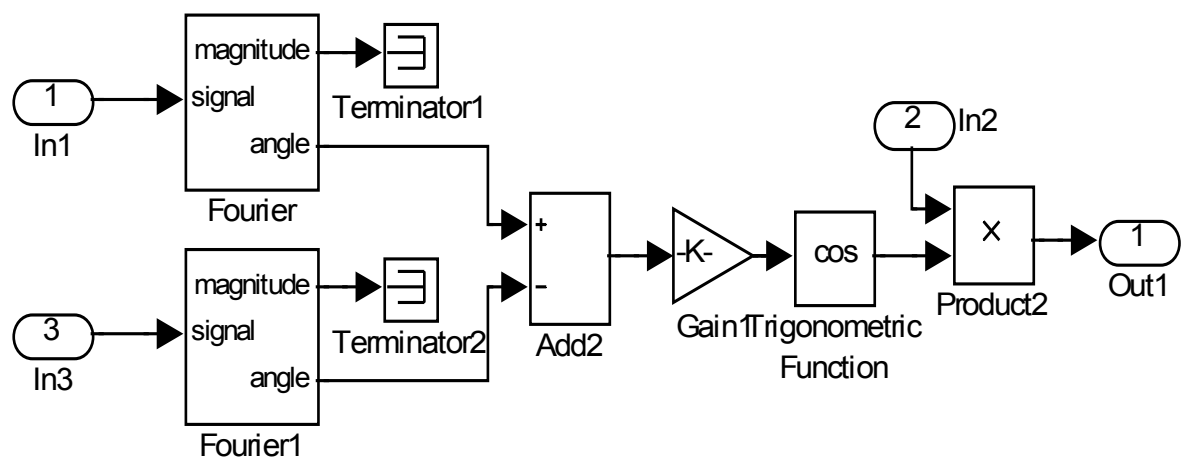

Fig. 17. The circuit of the module Subsystem 3 
The input voltage and current of BOOST active correcting circuit are shown in Figure 18, in which the power of factor is up to 0.99 . BOOST active correcting circuit is mainly used on occasions of high and medium power.

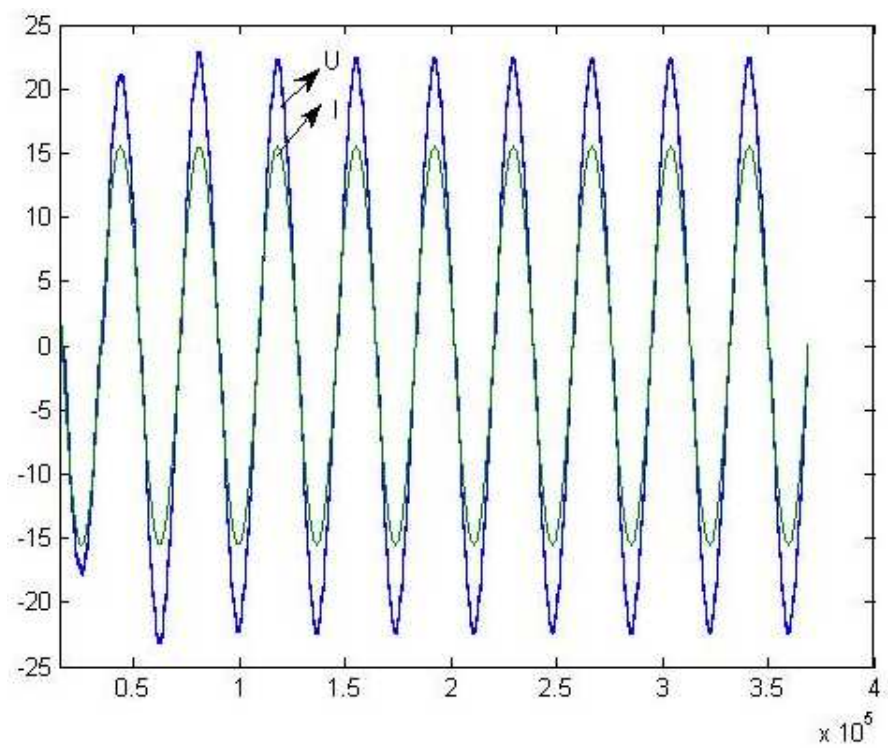

Fig. 18. Input voltage and current wave form of BOOST active correcting circuit

\section{Soft-switching Correcting Circuit Based on BOOST Circuit[2]}

By the use of active switch components, BOOST active correcting circuit drastically decreases the harmonic current in AC side, and increases power factor. But, with the use of active switch components, switch devices' off-losses increase, the stress of the voltage and current increases. In order to solve these problems, soft switch technology is introduced. The typical circuit of using soft switch technology is shown in Figure 19. The circuit is consisted of basic BOOST circuit and auxiliary resonant network. Auxiliary resonant network is comprised of auxiliary switch $\mathrm{Q}_{2}$, resonant inductor $\mathrm{L}_{\mathrm{a}}$, resonant capacitor $\mathrm{C}_{\mathrm{a}}$ and $\mathrm{C}_{\mathrm{r}}$, auxiliary diode $\mathrm{D}_{\mathrm{a}}, \mathrm{D}_{\mathrm{b}}$ and $\mathrm{D}_{\mathrm{c}}$.

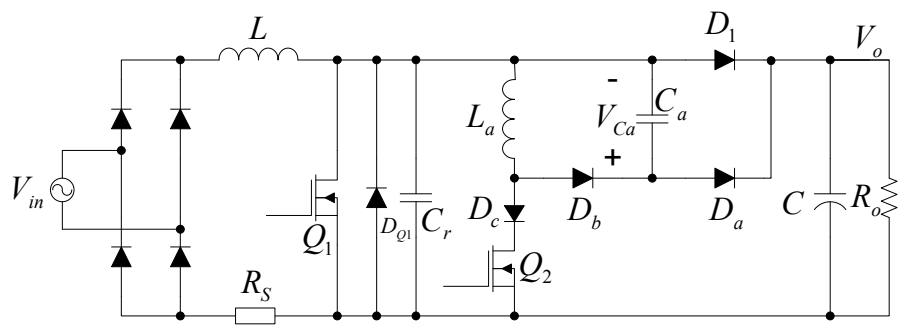

Fig. 19. Correcting circuit of typical soft-switching active power factor 
Auxiliary resonant network supplies ZVS/Zero-voltage opening conditions for main switch $Q_{1}$. The working procedure can be divided into 6 steps as the following:

(1) Assuming main switch $Q_{1}$ is off, and diode $D_{1}$ is conducted, inductance $L$ charges for capacitor $C$;

(2) When the main switch $Q_{1}$ is needed to be turned on, the auxiliary switch $Q_{2}$ is turned on in advance, the current of resonant inductance increases from zero linearly at the time. $D_{1}$ will be turned off when the current of $L_{a}$ equals to the one of $L$;

(3) When $D_{1}$ is turned off, resonant inductance $L_{a}$ and resonant capacitor $C_{r}$ is to form resonant circuit, $C_{r}$ voltage gradually decreases, and when it equals zero, the diode $D_{Q_{1}}$ in the main switch $Q_{1}$ is inducted, the resonant circuit stops vibrating, and the voltage of the $Q_{1}$ equals zero;

(4) Switching on $Q_{1}$ to realize ZVS;

(5) When $Q_{1}$ is on, $Q_{2}$ is turned off, then $L_{a}$ and $C_{a}$ is to form resonant circuit, but for the initial value of $C_{a}$ is zero, $Q_{2}$ is off at zero voltage; when voltage of $C_{a}$ equals to output voltage, the diode $D_{a}$ is conducted, and the current of La decreases linearly, when it decreases to zero, $D_{a}$ and $D_{b}$ are turned off;

(6) When the mains switch $Q_{1}$,is turned off , the current of inductance L charges for $C_{a}$ and $\mathrm{C}_{\mathrm{r}}$ respectively, for the initial voltage of capacitor $C_{r}$ is zero, the $Q_{1}$ is off under the condition of zero voltage; when the voltage of $C_{r}$ increases to as same as the output voltage, the voltage of $C_{a}$ already decreases to zero, diode $D_{a}$ and diode $D_{1}$ is conducted. Hereafter, repeating the front process.

Therefore, from the above analysis we can see that the main switch $Q_{1}$ is zero voltage turned on and turned off, which works in the mode of real ZVT model; auxiliary switch is zero current turned on and zero voltage turned off, which works on the model of the combination of ZCT (Zero Current Transition) and ZVT.

There are various controlling circuit of Boost power factor correction, among which, average current control is suitable to be used in occasions of high and medium voltage and it most widely used in APFC currently because that its THD (Total Harmonic Distortion) and EMI ( Electro Magnetic Interference) is small, it is not sensitive to noise, the switching frequency is fixed, and the error between inductive current peak value and average value is small, it is a kind of controlling method that used most widely in APFC at present. So, in correcting circuits for soft-switching power factor, average current controlling is chose.

In order to make sure that the main switch keeps turning on under zero voltage, and the auxiliary switching tube maintains conducted when the time the resonance voltage on $C_{r}$ 
decrease to zero, a fixed period of delaying time can be added, this period of time $t_{Z V T}=\frac{I_{I N_{P}} L_{a}}{V_{o}}+\frac{\pi}{2} \sqrt{L_{a} C_{r}}$ equals to the transition time of zero voltage under the condition of input voltage low limit and full loading. This is also the advanced conduction time of auxiliary switching tube than main switching tube.

The selecting of parameters as is shown in table 3.

\begin{tabular}{|l|l|l|l|l|l|}
\hline $\begin{array}{l}\text { Boost } \\
\text { Inductance L }\end{array}$ & $\begin{array}{l}\text { Filter } \\
\text { Capacitor C }\end{array}$ & $\begin{array}{l}\text { Auxiliary } \\
\text { Inductance } L_{a}\end{array}$ & $\begin{array}{l}\text { Auxiliary } \\
\text { Capacitor } C_{a}\end{array}$ & $\begin{array}{l}\text { Sampling } \\
\text { Resistance } R_{s}\end{array}$ & $\begin{array}{l}\text { Output } \\
\text { Load } R_{0}\end{array}$ \\
\hline $1.0 \mathrm{mH}$ & $450 \mu \mathrm{F}$ & $6 \mu \mathrm{H}$ & $3.6 \mathrm{nF}$ & $0.048 \Omega$ & $160 \Omega$ \\
\hline
\end{tabular}

Table 3. the selecting of parameters of correcting circuit components of soft-switching power factor

Power factor is shown in Figure 20, wave forms of input voltage and current are shown in Figure 21, and wave form of output voltage is shown in Figure 22. We can see that when emulation time reaches to $0.024 \mathrm{~s}$, the circuit tends to stable, power factor is also stable and power factor approaches to 1 . Although the power factor fluctuated after became stable, but the amplitude of fluctuation is very small.

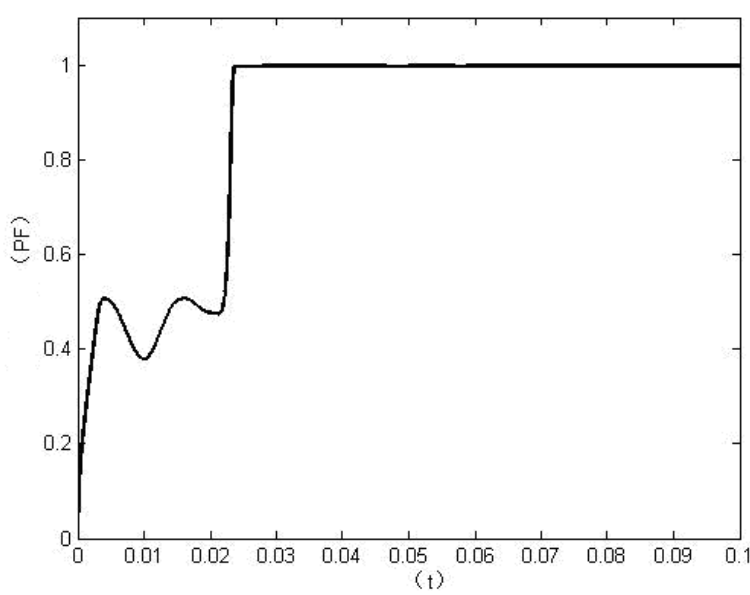

Fig. 20. The Power Factor of soft Switch BOOST 


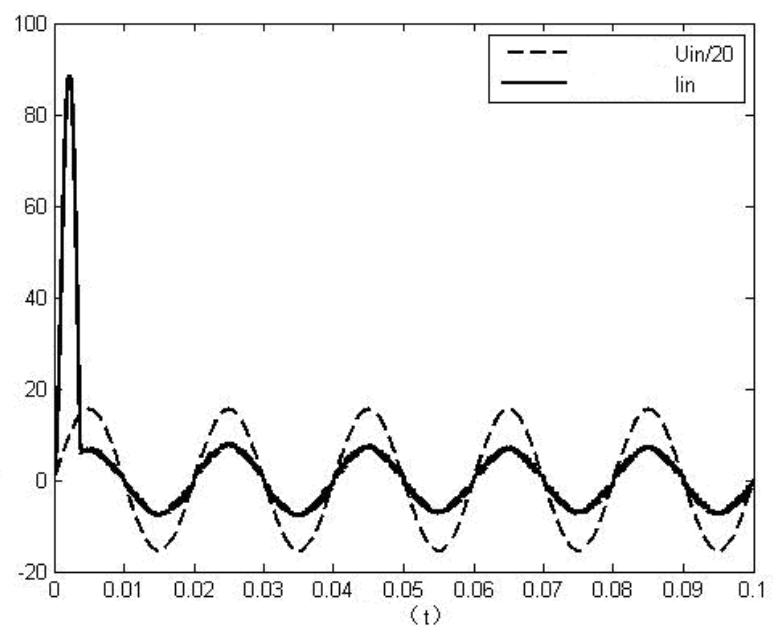

Fig. 21. Wave Forms of Input Voltage, Current of Soft Switch BOOST

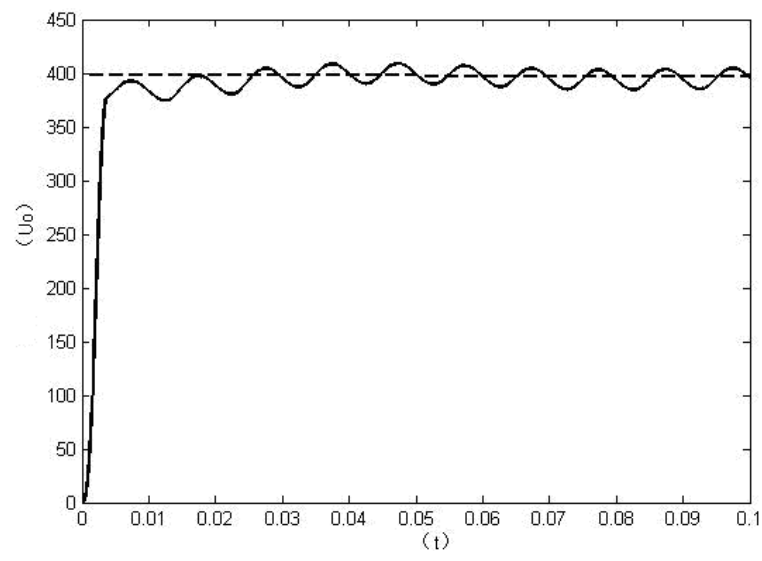

Fig. 22. Wave Form of Output Voltage

Figure 23 gives harmonic wave input current value of soft switching active power factor's correcting circuit and the comparing result with standard value of IEC61000-3-2A. We can see from the Figure that input current's 2、3.....19 harmonic wave, the current values are all much smaller than standard value in IEC61000-3-2A. 


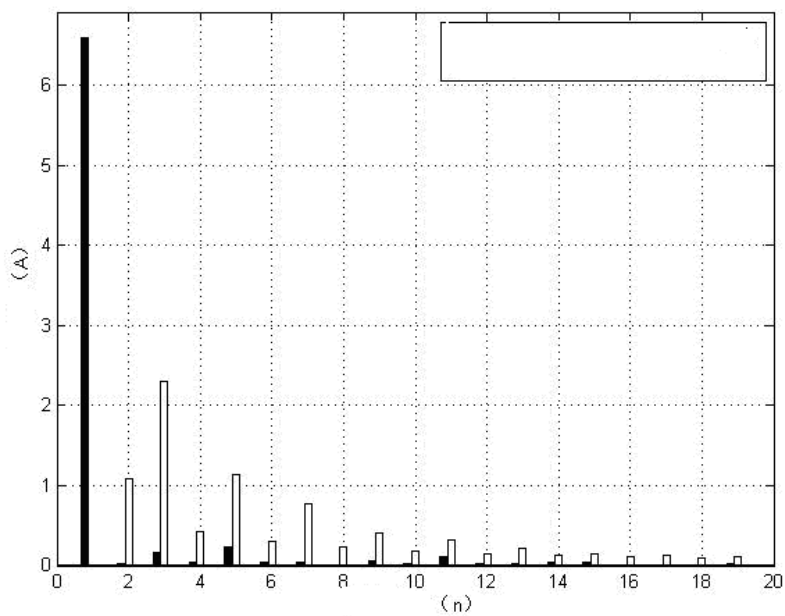

Fig. 23. Comparison of Circuit Input Harmonic Current Wave Value and Standard Value

\section{Power factor of three-phase AC/DC switching power supply with the load of pure resistance}

In single-phase uncontrolled rectifying circuit, if the load equivalent is a resistance, the input power factor is unit 1 . But in three-phase uncontrolled rectifying circuit, even the load is a resistance (see Figure 24), its power factor is only about 0.94 . The phase voltage and phase current wave form of the time being as are shown in Figure 25.

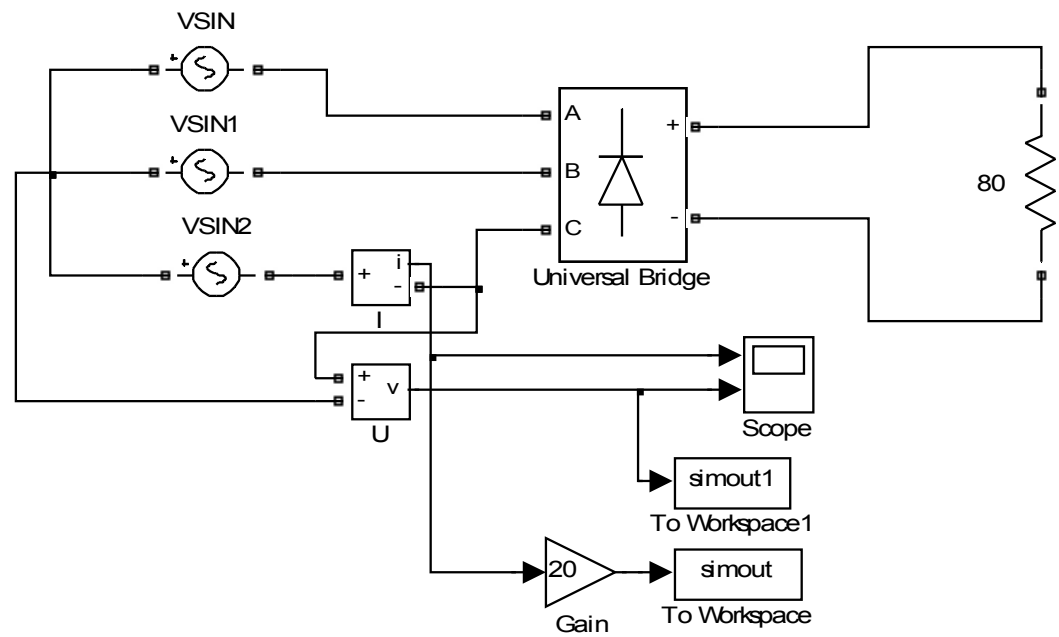

Fig. 24. Three-phase uncontrolled rectifier circuit with the load of pure resistance 


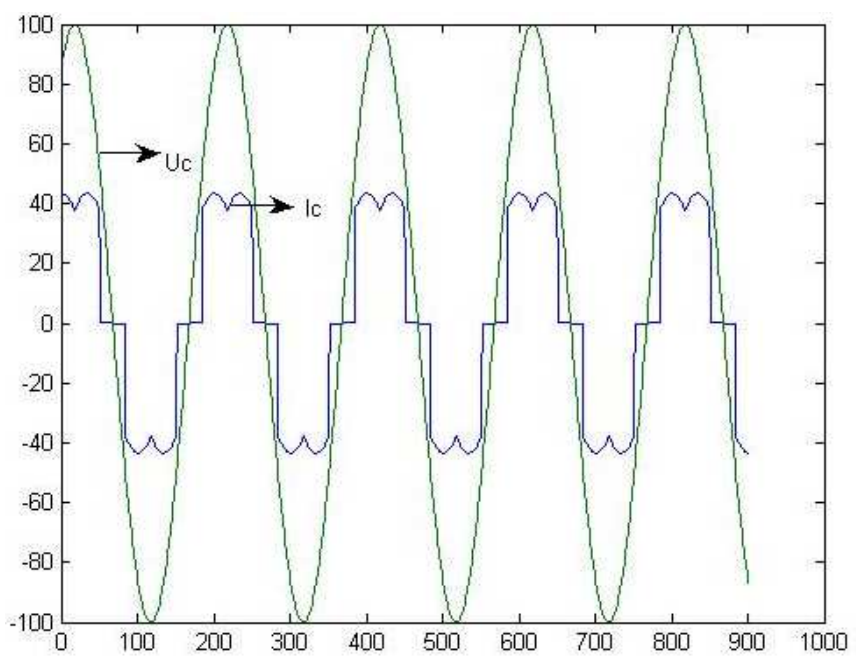

Fig. 25. Phase voltage and phase current wave forms of three-phase uncontrolled rectifier circuit with the load of pure resistance

\section{Three-phase Passive PFC Circuit of Series Connected Large Inductance}

Power factor correcting circuits of three phase AC/DC switch power source can be divided into passive PFC and active PFC. Active PFC can adopt three three-phase BOOST correcting circuit, but its application area is not as wide as the one of passive PFC. The most widely used of three-phase passive PFC is inductive circuit, the voltage and current of which are shown in Figure 26, and the power factor reach to 0.95 .

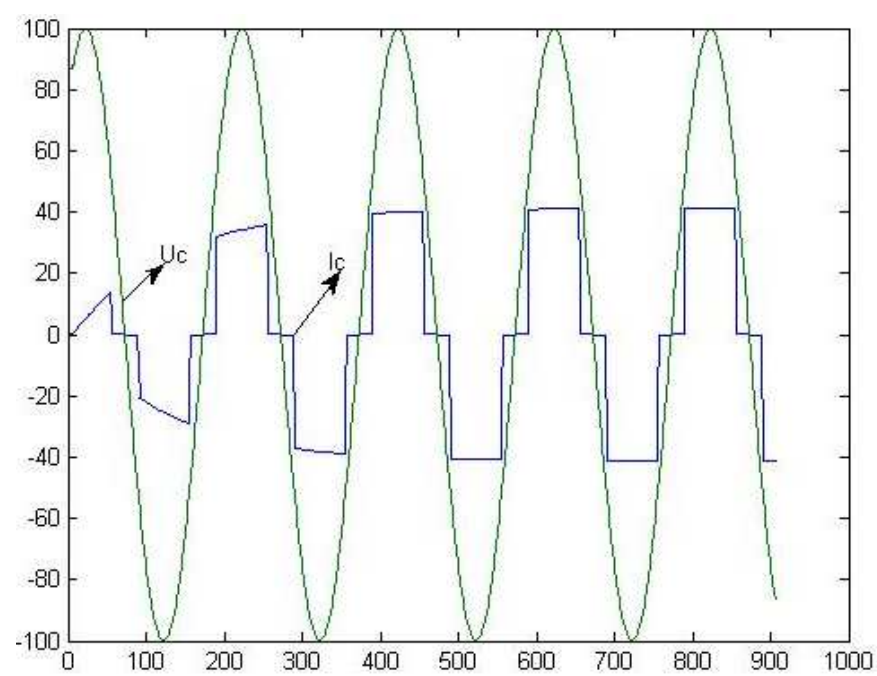

Fig. 26. Three-phase Current of Series Connected Large Inductance 


\section{An Improved Three-phase Passive PFC Circuit}

Figure 27 is a kind of improved three-phase passive power factor's correcting circuit, the circuit parameters of which has been optimized by using MATLAB. Figure 28 is its phase voltage and phase current form, and the power factor of which reaches to 0.991 .

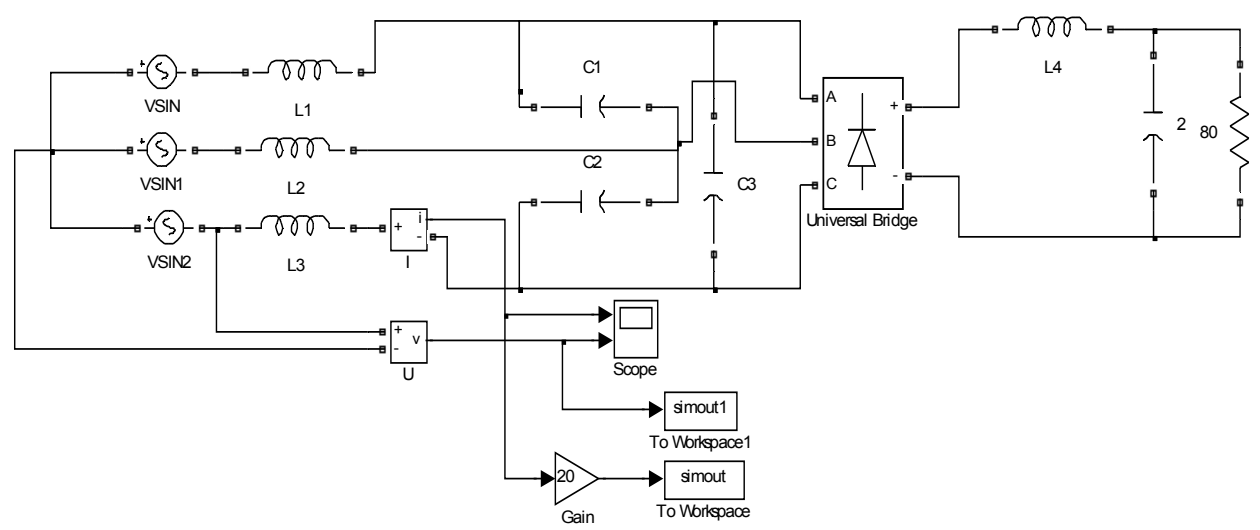

Fig. 27. The circuit of an improved three-phrase passive power factor correcting

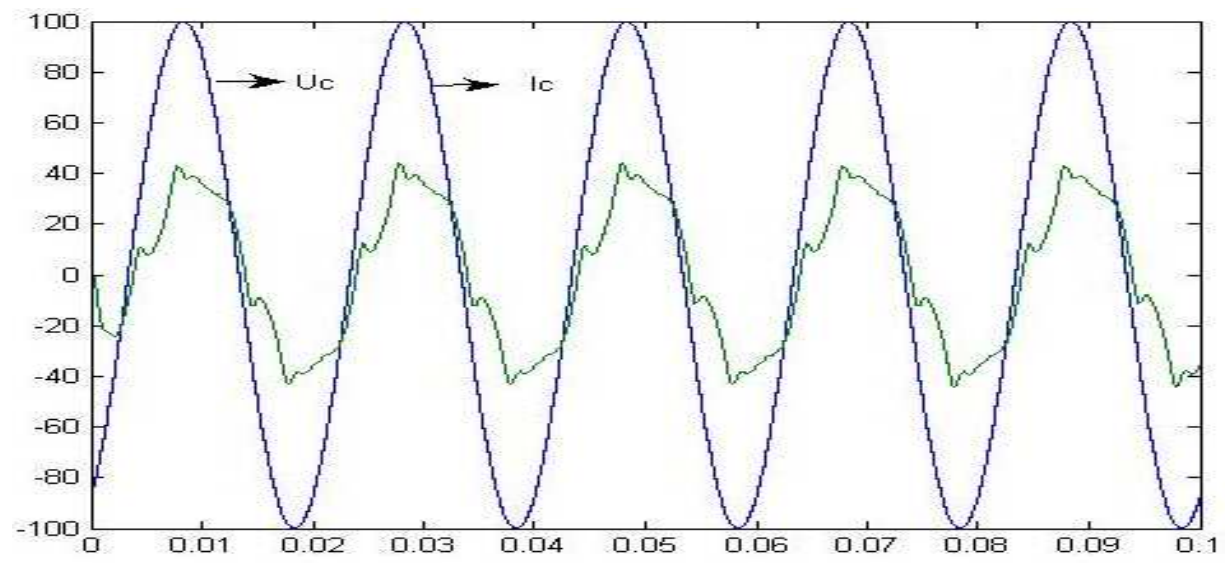

Fig. 28. The phase voltage and phase current form of an improved three-phase passive power factor's correcting circuit 


\section{References}

Ren Kaichun, Zhang Xuanqi, Tu Yaqing. The Emulation for the Maximum Power Factor of BOOST Circuit. ELECTRIC ENGINEERING, 2003(10)

Ren Kaichun, Zhang Xuanqi, Tu Yaqing, etc. The PSPICE Simulation for the Power Factor of Three- phase-switching-power. ELECTROTECHNICAL JOURNAL, 2003(8)

Ren Kaichun, Zhang Xuanqi, Zhang Xiaoqing, etc. The PSPICE Simulation and Optimization for the Power Factor Correction of Single-phase Switching Power Supply. ELECTRICAL AUTOMATION, 2003(5)

Ren Kaichun, Yan Zhiqiang, Wang Yongmin. Soft-switching APFC circuit based on Matlab. ELECTRIC POWER AUTOMATION EQUIPMENT, 2007(8)

Wang Huitao, Ren Kaichun, Qiang Shengze, Jing Youquan. Imitation Analysis and Optimization of a Single-Phase Switch Electric Source Power Factor. ELECTRIC ENGINEERING, 2005(11)

Wang Yongmin, Ren Kaichun, Jing Youquan. The Caspoc Simulation Analysis and Optimization of a three-Phase Switching Power Supply PFC Circuit. ELECTRIC AGE,2006(11) 


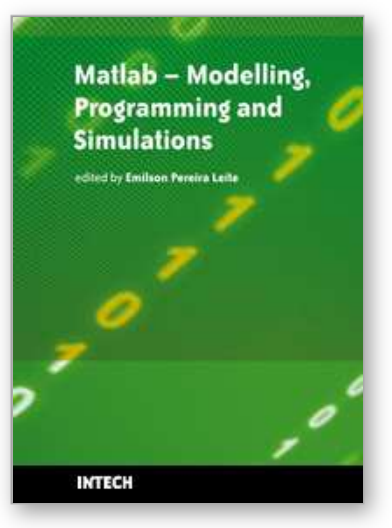

\author{
Matlab - Modelling, Programming and Simulations \\ Edited by Emilson Pereira Leite
}

ISBN 978-953-307-125-1

Hard cover, 426 pages

Publisher Sciyo

Published online 05, October, 2010

Published in print edition October, 2010

This book is a collection of 19 excellent works presenting different applications of several MATLAB tools that can be used for educational, scientific and engineering purposes. Chapters include tips and tricks for programming and developing Graphical User Interfaces (GUIs), power system analysis, control systems design, system modelling and simulations, parallel processing, optimization, signal and image processing, finite different solutions, geosciences and portfolio insurance. Thus, readers from a range of professional fields will benefit from its content.

\title{
How to reference
}

In order to correctly reference this scholarly work, feel free to copy and paste the following:

Ren Kaichun, He Chunhan, Su Dan, Wang Yongli, Zhang Xingqi, Lio Xaiojun, Gung Lihong, Zhao Ying and Liu Peng (2010). Matlab Simulations for Power Factor Correction of Switching Power, Matlab - Modelling, Programming and Simulations, Emilson Pereira Leite (Ed.), ISBN: 978-953-307-125-1, InTech, Available from: http://www.intechopen.com/books/matlab-modelling-programming-and-simulations/matlab-simulations-forpower-factor-correction-pfc-of-switching-power

\section{INTECH}

open science | open minds

\section{InTech Europe}

University Campus STeP Ri Slavka Krautzeka 83/A 51000 Rijeka, Croatia Phone: +385 (51) 770447 Fax: +385 (51) 686166 www.intechopen.com

\section{InTech China}

Unit 405, Office Block, Hotel Equatorial Shanghai No.65, Yan An Road (West), Shanghai, 200040, China 中国上海市延安西路65号上海国际贵都大饭店办公楼 405 单元 Phone: +86-21-62489820

Fax: $+86-21-62489821$ 
(C) 2010 The Author(s). Licensee IntechOpen. This chapter is distributed under the terms of the Creative Commons Attribution-NonCommercialShareAlike-3.0 License, which permits use, distribution and reproduction for non-commercial purposes, provided the original is properly cited and derivative works building on this content are distributed under the same license. 